\title{
Determination of Ferrous Iron in Ferric Chloride Hexahydrate
}

\author{
Bai Xiaoguang ${ }^{1}$, Wang Zhengda ${ }^{1}$, Wu Xudong ${ }^{1}$, Duan Shufen ${ }^{1}$, Liu Aihua ${ }^{1}$, Cheng Xiao ${ }^{2}$ \\ ${ }^{1}$ Shanghai Gongji Chemical Co., Ltd., Shanghai, China \\ ${ }^{2}$ Qingdao Guofeng Pharmaceutical Co., Ltd, Qingdao, China
}

Email address:

languanghuaxue@126.com (Bai Xiaoguang),wang_zenda@163.com (Wang Zhengda)

\section{To cite this article:}

Bai Xiaoguang, Wang Zhengda, Wu Xudong, Duan Shufen, Liu Aihua, Cheng Xiao. Determination of Ferrous Iron in Ferric Chloride Hexahydrate. International Journal of Pharmacy and Chemistry. Vol. 7, No. 1, 2021, pp. 1-4. doi: 10.11648/j.ijpc.20210701.11

Received: March 25, 2019; Accepted: June 24, 2020; Published: February 10, 2021

\begin{abstract}
Objective: As a pharmaceutical raw material, ferric chloride hexahydrate has been included in the British Pharmacopoeia, the European Pharmacopoeia (2008) and the United States Pharmacopoeia (2015), and there are detailed discussions on quality standards and testing methods. Ferric chloride hexahydrate has not been included in the Chinese Pharmacopoeia. This study is the part of research to establish a spectrophotometric method for the determination of ferrous iron in ferric chloride hexahydrate. In this study, the two methods were discussed in detail, and the spectrophotometric method for detecting the content of ferrous iron in ferric chloride hexahydrate was proposed. Methods: The detection method on ferrous iron in ferric chloride hexahydrate among European pharmacopoeia, United States pharmacopoeia and Chemical Reagent Ferric Chloride Hexahydrate (HG/T3474-2014) of China's Chemical Industry were compared. The last two methods were not easy to operation. On the basis of the European pharmacopoeia, a method was proposed that after $\mathrm{Fe}^{3+}$ were screened with $\mathrm{H}_{3} \mathrm{PO}_{4}, \mathrm{Fe}^{2+}$ was measured by spectrophotometry, and the method was verified by experiments. Results and Conclusion: The spectrophotometry method is easy to operate and has good reproducibility. The content of ferrous iron can be calculated semi-quantitatively by masking ferric iron with $\mathrm{H}_{3} \mathrm{PO}_{4}$ and spectrophotometric determination of ferrous ion content. Therefore, the method established in this study can more clearly detect whether the ferrous content in ferric chloride hexahydrate is up to standard.
\end{abstract}

Keywords: Ferrous Ion, Ferric Chloride Hexahydrate, Spectrophotometry, Quality Control

\section{Preface}

As a pharmaceutical raw material, ferric chloride hexahydrate has been included in the British Pharmacopoeia, the European Pharmacopoeia (2008) and the United States Pharmacopoeia (2015) [1-5], and there are detailed discussions on quality standards and testing methods. Ferric chloride hexahydrate has not been included in the Chinese Pharmacopoeia [6], but it has been widely used as a pharmaceutical raw material by many domestic pharmaceutical companies. Regarding its quality indicators and testing methods, domestic pharmaceutical companies have their own corporate standards, but they vary according to the understanding of the quality inspection personnel of each enterprise, and the testing methods are not the same. The method for determining the content of ferrous iron in ferric chloride hexahydrate is basically divided into two types at home and abroad: one is the direct color development method of potassium ferricyanide represented by American Chemical Society (ACS); The second is the phosphate masking represented by the European Pharmacopoeia - potassium ferricyanide coloring method. In this study, the two methods were discussed in detail, and the spectrophotometric method for detecting the content of ferrous iron in ferric chloride hexahydrate was proposed.

\section{Instruments and Reagents}

\subsection{Instruments}

722 spectrophotometer (Shanghai Jinghua Technology Instrument Co., Ltd.). 


\subsection{Reagents}

Potassium ferricyanide (Shanghai Qianshun Chemical Reagent Co., Ltd., batch number 1401107), 5\% potassium ferricyanide solution prepared on the test day; phosphoric acid (Shanghai Lingfeng Chemical Reagent Co., Ltd., batch number 20151009); sulfuric acid heptahydrate Yatie (Shenzhen Pharmaceutical Group Chemical Reagent Co., Ltd., batch number 10012118) $\mathrm{Fe}^{2+}$ concentration of $0.1 \mathrm{mg} / \mathrm{mL}$ stock solution (weigh $0.250 \mathrm{~g} \mathrm{FeSO}_{4} \cdot 7 \mathrm{H}_{2} \mathrm{O}$, add $\mathrm{H} 2 \mathrm{SO} 45 \mathrm{~mL}$ dissolved and diluted into $500 \mathrm{~mL}$ volumetric flask); $\mathrm{Fe}^{2+}$ concentration of $0.01 \mathrm{mg} / \mathrm{mL}$ solution (take $10 \mathrm{~m}$ $\mathrm{Fe}^{2+}$ concentration $0.1 \mathrm{mg} / \mathrm{mL}$ stock solution, diluted to $100 \mathrm{~mL}$ volumetric flask, ready for use) Ferric chloride solution of hexahydrate $\left(\mathrm{FeCl}_{3} \cdot 6 \mathrm{H}_{2} \mathrm{O}\right.$, Sinopharm Chemical Reagent Co., Ltd., batch number 10011918); hydrochloric acid, Sinopharm Chemical Reagent Co., Ltd., batch number 10011018).

\section{Methods and results}

\subsection{Principle of the Method}

$\mathrm{K}_{3} \mathrm{Fe}(\mathrm{CN})_{6}$ solution and the divalent iron salt immediately form the Teng's blue precipitate, and its composition is $\mathrm{Fe}^{3}\left[\mathrm{Fe}(\mathrm{CN})_{6}\right]_{2}$ [7-9]. At this time, the ferric iron does not interfere, because $\mathrm{Fe}^{3+}$ and $\mathrm{K}_{3} \mathrm{Fe}(\mathrm{CN})_{6}$ only produce a light green-brown solutio [10-12], and the $\mathrm{Fe}^{3+}$ complex was masked with $\mathrm{H}_{3} \mathrm{PO}_{4}$ to make it colorless. The chemical reaction formula is as follows:

$$
3 \mathrm{FeCl}_{2}+2 \mathrm{~K}_{3} \mathrm{Fe}(\mathrm{CN})_{6} \rightarrow \mathrm{Fe}_{3}\left[\mathrm{Fe}(\mathrm{CN})_{6}\right]_{2}+6 \mathrm{KCl}
$$

\subsection{Method Establishment}

\subsubsection{ACS Detection Method}

Method: Weigh $0.5 \mathrm{~g}$ of sample, dissolve it in $20 \mathrm{~mL}$ hydrochloric acid $(1 \rightarrow 19)$, and add $0.05 \mathrm{~mL}$ of newly prepared $5 \% \mathrm{~K}_{3} \mathrm{Fe}(\mathrm{CN})_{6}$. If there is no blue-green color in $1 \mathrm{~min}$, the $\mathrm{Fe}^{2+}$ content of the sample is considered no more than $0.002 \%$.

Exploratory test 1: Take different amounts of $\mathrm{Fe}^{2+}$, add different amounts of hydrochloric acid, add 2 drops of 5\% $\mathrm{K}_{3} \mathrm{Fe}(\mathrm{CN})_{6}$, and measure the absorbance after color development at $1 \mathrm{~min}$ and $10 \mathrm{~min}$. The wavelength of the incident light was yellow $(\lambda=570 \mu \mathrm{m})$, and the length of the cuvette was $5 \mathrm{~mm}$, which was measured with a 722 spectrophotometer. The results are shown in Table 1 and Table 2. It can be seen that when $1 \mathrm{~mL}$ hydrochloric acid is added to the $25 \mathrm{~mL}$ test solution, the color is basically not developed, especially when the $\mathrm{Fe}^{2+}$ content is as low as $10 \mu \mathrm{g}$, the absorbance is lower. In this case, it is impossible to distinguish by visual inspection

Table 1. Absorbance at different iron contents at 1 minute.

\begin{tabular}{|c|c|c|c|c|c|c|}
\hline HCL $\quad \mathrm{Fe}^{2+}$ content & $10 \mu \mathrm{g}$ & $20 \mu \mathrm{g}$ & $30 \mu \mathrm{g}$ & $40 \mu \mathrm{g}$ & $50 \mu \mathrm{g}$ & $60 \mu \mathrm{g}$ \\
\hline $0 \mathrm{~mL}$ & 0.093 & 0.186 & 0.283 & 0.366 & 0.458 & 0.562 \\
\hline $0.5 \mathrm{~mL}$ & 0.005 & 0.013 & 0.049 & 0.059 & 0.183 & 0.408 \\
\hline $1 \mathrm{~mL}$ & 0.005 & 0.009 & 0.007 & 0.011 & 0.015 & 0.017 \\
\hline $1.5 \mathrm{~mL}$ & 0.010 & 0.009 & 0.019 & 0.008 & 0.007 & 0.012 \\
\hline
\end{tabular}

Table 2. Absorbance at different iron contents at 10 minute.

\begin{tabular}{|c|c|c|c|c|c|c|}
\hline $\mathrm{HCL}$ & $10 \mu \mathrm{g}$ & $20 \mu \mathrm{g}$ & $30 \mu \mathrm{g}$ & $40 \mu \mathrm{g}$ & $50 \mu \mathrm{g}$ & $60 \mu \mathrm{g}$ \\
\hline $0 \mathrm{~mL}$ & 0.106 & 0.193 & 0.287 & 0.374 & 0.465 & 0.570 \\
\hline $0.5 \mathrm{~mL}$ & 0.005 & 0.014 & 0.123 & 0.237 & 0.417 & 0.574 \\
\hline $1 \mathrm{~mL}$ & 0.005 & 0.010 & 0.010 & 0.009 & 0.016 & 0.029 \\
\hline $1.5 \mathrm{~mL}$ & 0.010 & 0.005 & 0.019 & 0.006 & 0.012 & 0.012 \\
\hline
\end{tabular}

Table 3. Absorbance comparison of ferrous iron under different conditions.

\begin{tabular}{llllll}
\hline Time & $\mathbf{( 1 )}$ & $\mathbf{( 2 )}$ & $\mathbf{( 3 )}$ & $\mathbf{( 4 )}$ & $\mathbf{( 5 )}$ \\
\hline $1 \mathrm{~min}$ & 0.093 & 0.005 & 0.015 & 0.059 & 0.187 \\
$2 \mathrm{~min}$ & 0.099 & 0.005 & 0.014 & 0.058 & 0.186 \\
$3 \mathrm{~min}$ & 0.101 & 0.005 & 0.015 & 0.058 & 0.188 \\
$4 \mathrm{~min}$ & 0.102 & 0.006 & 0.013 & 0.059 & 0.196 \\
$5 \mathrm{~min}$ & 0.104 & 0.004 & 0.013 & 0.059 & 0.198 \\
$6 \mathrm{~min}$ & 0.105 & 0.004 & 0.013 & 0.059 & 0.207 \\
$7 \mathrm{~min}$ & 0.105 & 0.005 & 0.014 & & 0.223 \\
$8 \mathrm{~min}$ & 0.106 & 0.005 & 0.016 & & 0.239 \\
$9 \mathrm{~min}$ & 0.106 & 0.003 & 0.016 & & 0.251 \\
$10 \mathrm{~min}$ & 0.107 & 0.003 & 0.022 & & 0.254 \\
$11 \mathrm{~min}$ & 0.107 & 0.003 & 0.023 & & 0.252 \\
$12 \mathrm{~min}$ & 0.107 & 0.005 & 0.021 & & 0.251 \\
$13 \mathrm{~min}$ & 0.108 & 0.005 & 0.023 & & 0.251 \\
$14 \mathrm{~min}$ & 0.108 & 0.004 & 0.018 & & 0.251 \\
$15 \mathrm{~min}$ & 0.108 & 0.005 & 0.020 & & 0.251 \\
\hline
\end{tabular}

Exploratory Test 2: The test was carried out under the following conditions. Condition $\mathrm{A}$, take $10 \mu \mathrm{g} \mathrm{Fe}^{2+}$ standard solution without adding hydrochloric acid, dilute to $25 \mathrm{~mL}$, add 1 drop of $5 \% \mathrm{~K}_{3} \mathrm{Fe}(\mathrm{CN})_{6}$; condition $\mathrm{B}$, take $10 \mu \mathrm{g} \mathrm{Fe}{ }^{2+}$ standard solution, add $1 \mathrm{~mL}$ hydrochloric acid, dilute to $25 \mathrm{~mL}$, add 1 drop of $5 \% \mathrm{~K}_{3} \mathrm{Fe}(\mathrm{CN})_{6}$; Condition $\mathrm{C}$, take $50 \mu \mathrm{g} \mathrm{Fe}^{2+}$ standard solution, add $1 \mathrm{~mL}$ hydrochloric acid, dilute to $25 \mathrm{~mL}$, add 1 drop $5 \% \quad \mathrm{~K}_{3} \mathrm{Fe}(\mathrm{CN})_{6}$; condition $\mathrm{D}$, take $0.5 \mathrm{gFeCl}_{3} \cdot 6 \mathrm{H}_{2} \mathrm{O}$, add $1 \mathrm{~mL}$ hydrochloric acid, dilute to $25 \mathrm{~mL}$ without adding $\mathrm{K}_{3} \mathrm{Fe}(\mathrm{CN})_{6}$; Condition $\mathrm{E}$, take $0.5 \mathrm{~g}$ $\mathrm{FeCl}_{3} \cdot 6 \mathrm{H}_{2} \mathrm{O}$, add $1 \mathrm{~mL}$ hydrochloric acid, dilute to $25 \mathrm{~mL}$, add 1 drop of $5 \% \mathrm{~K}_{3} \mathrm{Fe}(\mathrm{CN})_{6}$. The absorbance of the solution was measured using a Model 722 spectrophotometer. The results are shown in Table 3. It can be seen that in the presence of 1 $\mathrm{mL}$ of hydrochloric acid, not only the absorbance of $10 \mu \mathrm{g}$ of 
$\mathrm{Fe}^{2+}$ is extremely low, but the absorbance of $50 \mu \mathrm{g}$ of $\mathrm{Fe}^{2+}$ is also less than 0.02 , but how the absorbance $(>0.2)$ of the sample solution (Condition E) is generated. This is the biggest problem with the ACS method. In addition, without blue-green is not certain that the $\mathrm{Fe}^{2+}$ content is not more than $0.002 \%$. Such a small amount of $\mathrm{Fe}^{2+}(10 \mu \mathrm{g})$ relies on visual inspection; the randomness is too large. This is the second problem of the ACS method. Moreover, since the color of the ferric iron is too dark, the detection sampling volume should not be too large.

\subsubsection{Test Methods for China's Chemical Industry}

Method: The quality index and detection method of ferric chloride hexahydrate in China's chemical industry standard [13] is basically derived from the ACS method. Weigh $0.5 \mathrm{~g}$ sample, dissolve it in $20 \mathrm{~mL}$ anaerobic water, add $1 \mathrm{~mL}$ hydrochloric acid and 1 drop of freshly prepared 5\% $\mathrm{K}_{3} \mathrm{Fe}(\mathrm{CN})_{6}$, shake it and let it stand for $10 \mathrm{~min}$. The solution should be dark blue-green and not deeper than the standard colorimetric solution. Among them, the standard colorimetric solution is prepared by weighing $0.5 \mathrm{~g}$ of ferrous iron-free ferric chloride hexahydrate (the solution does not appear blue-green according to the above method) and $0.01 \mathrm{mg} \mathrm{Fe}$

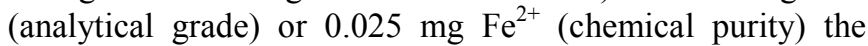
ferrous $\left(\mathrm{Fe}^{2+}\right)$ standard solution, is treated the same as the sample.

Problem: There are three disadvantages of this method: first, that $1 \mathrm{~mL}$ of hydrochloric acid is used in the ACS method; second, the sample volume is too little, and the third is to use ferrous-free ferric chloride hexahydrate. Ferrousfree ferric chloride hexahydrate is hard to find. According to the ACS method, no blue-green color indicates that the ferrous content is not more than $0.002 \%$, and it is not meaning free of ferrous iron. Moreover, the author's test shows that the content of ferrous iron in the sample may still be greater than $0.002 \%$ or even higher without blue-green color, but it is just visually undetectable.

\subsubsection{European Pharmacopoeia Detection Method}

Method (phosphoric acid masking - potassium ferricyanide coloring method): To $10 \mathrm{~mL}$ sample solution (containing $1 \mathrm{~g}$ sample), add $1 \mathrm{~mL} \mathrm{H}_{2} \mathrm{O}$ and 1 drop of $5 \% \mathrm{~K}_{3} \mathrm{Fe}(\mathrm{CN})_{6}$ solution, then add $4 \mathrm{~mL} \mathrm{H}_{3} \mathrm{PO}_{4}$. After $10 \mathrm{~min}$, the blue color in the test solution should not be deeper than the standard solution. The standard solution was $1 \mathrm{~mL}$ freshly prepared ferrous sulfate solution $\left(0.25 \mathrm{~g} / \mathrm{L} \mathrm{FeSO}_{4} \cdot 7 \mathrm{H}_{2} \mathrm{O}\right)$ and $10 \mathrm{~mL} \mathrm{H}_{2} \mathrm{O}$, it treated simultaneously with the sample. Analysis of the detection method of the European Pharmacopoeia, masking the ferric chloride with $\mathrm{H}_{3} \mathrm{PO}_{4}$, the method is simple and clear. However, if a spectrophotometer is used for the detection, a sample blank solution should be prepared, that is, the sample $\left(\mathrm{FeCl}_{3} \cdot 6 \mathrm{H}_{2} \mathrm{O}\right)$ solution is mixed with the same $\mathrm{H}_{3} \mathrm{PO}_{4}$. When calculating the ferrous content, the absorbance of the sample blank solution should be subtracted from the absorbance of the sample solution.

\subsection{4. $\mathrm{H}_{3} \mathrm{PO}_{4}$ Masking $\mathrm{Fe}^{3+}$ Test}

Add $1 \mathrm{~g}$ of $\mathrm{FeCl}_{3} \cdot 6 \mathrm{H}_{2} \mathrm{O}$ and $25 \mathrm{~mL}$ of $\mathrm{H}_{2} \mathrm{O}$ to each of the 4 colorimetric tubes, and then add $4,6,8,10 \mathrm{~mL}$ of $\mathrm{H}_{3} \mathrm{PO}_{4}$, shake well, and measure the absorbance. The results are shown in Table 4 . It can be seen that $10 \mathrm{~mL} \mathrm{H}_{3} \mathrm{PO}_{4}$ has the best masking effect. In order to save $\mathrm{H}_{3} \mathrm{PO}_{4}$ and to be as consistent as possible with the European Pharmacopoeia method, I chose $8 \mathrm{~mL} \mathrm{H}_{3} \mathrm{PO}_{4}$ (solution volume before adding $\mathrm{H}_{3} \mathrm{PO}_{4}$ is $25 \mathrm{~mL}$ ) and the volume of solution of the European Pharmacopoeia method before adding $4 \mathrm{~mL} \mathrm{H}_{3} \mathrm{PO}_{4}$ is $11 \mathrm{~mL}$.

Table 4. $\mathrm{H}_{3} \mathrm{PO}_{4}$ Masking $\mathrm{Fe}^{3+}$ test $=570 \mu \mathrm{m}, \mathrm{h}=50 \mathrm{~mm}$.

\begin{tabular}{lllll}
\hline Time & $\mathbf{4 m L}$ & $\mathbf{6 m L}$ & $\mathbf{8 m L}$ & $\mathbf{1 0 m L}$ \\
\hline $2 \mathrm{~min}$ & 0.043 & 0.041 & 0.035 & 0.002 \\
$3 \mathrm{~min}$ & 0.041 & 0.040 & 0.034 & 0.002 \\
$4 \mathrm{~min}$ & 0.042 & 0.040 & 0.033 & 0.001 \\
$5 \mathrm{~min}$ & 0.041 & 0.042 & 0.033 & 0.001 \\
$6 \mathrm{~min}$ & 0.042 & 0.041 & 0.036 & 0.001 \\
\hline
\end{tabular}

\subsubsection{Spectrophotometric Detection of Ferrous Iron}

According to the European Pharmacopoeia method, the method for detecting ferrous iron in ferric chloride hexahydrate is to take four $50 \mathrm{ml}$ colorimetric tubes, numbered A, B, C, and D. Add $50 \mu \mathrm{g}$ of $\mathrm{Fe}^{2+}$ standard solution to the tube A and D. Add 1 gram of sample to each of the $\mathrm{B}$ tube, $\mathrm{C}$ tube, and $\mathrm{D}$ tube, and dissolve with a small amount of $\mathrm{H}_{2} \mathrm{O}$; dilute the 4 tube solutions to $25 \mathrm{ml}$ with $\mathrm{H}_{2} \mathrm{O}$, shake well; go to tube $\mathrm{A}$, tube $\mathrm{C}$, and tube $\mathrm{D}$, Add 2 drops of $5 \% \mathrm{~K}_{3} \mathrm{Fe}(\mathrm{CN})_{6}$ solution, shake well; add $8 \mathrm{~mL} \mathrm{H}_{3} \mathrm{PO}_{4}$ to each of the 4 tubes, shake well [where the $\mathrm{D}$ tube only plays the role of supervising the sample, its color must be deeper than the A tube, otherwise the sample may contain an oxidant (such as $\mathrm{Cl} 2$ ). If knowing there is no oxidant in the sample, the tube D may not be used. After 10 minutes, the absorbance is determined by the 722 spectrophotometer $=570 \mu \mathrm{m}, \mathrm{H}=50$ $\mathrm{mm}$, calculate the content of ferrous iron in the sample using the following formula

$$
x=50(C-B) / A
$$

Table 5. Verify test results (absorbance).

\begin{tabular}{|c|c|c|c|}
\hline Time & $50 \mu \mathrm{g} \mathrm{Fe}^{2+}$ & $\begin{array}{l}\text { 1gSample } \\
\text { Blank }\end{array}$ & $\begin{array}{l}\text { 1gSinopharm } \\
\text { Sample }\end{array}$ \\
\hline olmin & 0.208 & 0.054 & 0.106 \\
\hline $2 \mathrm{~min}$ & 0.199 & 0.050 & 0.109 \\
\hline $3 \mathrm{~min}$ & 0.194 & 0.049 & 0.113 \\
\hline $4 \mathrm{~min}$ & 0.192 & 0.049 & 0.117 \\
\hline $5 \mathrm{~min}$ & 0.189 & 0.049 & 0.121 \\
\hline $6 \mathrm{~min}$ & 0.187 & 0.049 & 0.124 \\
\hline $7 \mathrm{~min}$ & 0.186 & 0.048 & 0.126 \\
\hline $8 \mathrm{~min}$ & 0.185 & 0.049 & 0.129 \\
\hline $9 \mathrm{~min}$ & 0.184 & 0.050 & 0.132 \\
\hline $10 \mathrm{~min}$ & 0.183 & 0.049 & 0.134 \\
\hline $11 \mathrm{~min}$ & 0.181 & 0.048 & 0.135 \\
\hline $12 \mathrm{~min}$ & 0.182 & 0.049 & 0.138 \\
\hline $13 \mathrm{~min}$ & 0.181 & 0.050 & 0.139 \\
\hline $14 \mathrm{~min}$ & 0.180 & 0.048 & 0.140 \\
\hline $15 \mathrm{~min}$ & 0.179 & 0.049 & 0.141 \\
\hline $16 \mathrm{~min}$ & 0.178 & 0.048 & 0.143 \\
\hline $17 \mathrm{~min}$ & 0.178 & 0.048 & 0.144 \\
\hline $18 \mathrm{~min}$ & 0.178 & 0.048 & 0.146 \\
\hline $19 \min$ & 0.177 & 0.048 & 0.146 \\
\hline $20 \mathrm{~min}$ & 0.177 & 0.048 & 0.147 \\
\hline
\end{tabular}




\subsection{Experimental Verification}

Take the $\mathrm{FeCl}_{3} \cdot 6 \mathrm{H}_{2} \mathrm{O}$ sample of Sinopharm Chemical Reagent Co., Ltd. and measure according to the method of 2.2.5. The results are shown in Table 5. Since the absorbance of $50 \mu \mathrm{g} \mathrm{Fe}^{2+}$ standard solution and sample solution changes with time, therefore, the time limit should be specified, and still take the European Pharmacopoeia 10min as the standard. Calculated according to formula 1, the content of ferrous iron in the sample is obtained.

\section{Discussion}

When the content of $\mathrm{Fe}^{2+}$ in the sample is under very strict requirement, such as $\mathrm{Fe}^{2+}$ not more than $50 \times 10^{-6}$, or even no more than $20 \times 10^{-6}$, it should be considered that ferric chloride hexahydrate is not very stable. Ferric chloride hexahydrate is a very strong oxidant, and it is very active and has obvious disproportionation. When the aqueous solution is directly heated on an electric furnace, and even the hot solution is filtered by a filter paper filter cloth or a PP microporous membrane, it can generate $\mathrm{Fe}^{2+}$ [14-15]. Ferric chloride hexahydrate is especially sensitive to light, and disproportionation is easy to occur under illumination, and ferrous iron is automatically generated. For example, ferric chloride hexahydrate having a $\mathrm{Fe}^{2+}$ content of $0.002 \%$ is placed in a test tube, and after being placed outdoors for 10 days, the $\mathrm{Fe}^{2+}$ content becomes $0.22 \%$, which can be increased by 100 times. Therefore, the packaging and storage of its products is very important. Only to be absolutely protected from light, the ferrous iron will no longer be produced or the growth rate will slow down. When testing the ferrous content of the product, the package should be opened newly. Do not take samples from the product that has been opened for a long time. If the ferrous test requirements are very strict during production, try not to use ferric chloride hexahydrate when the package is opened for a long time.

The detection method of the European Pharmacopoeia takes $50 \mu \mathrm{g}$ of $\mathrm{Fe}^{2+}$ standard solution, which is 5 times of the ACS method $(10 \mu \mathrm{g})$. The blue-green color is clear, and there is no plausible and ambiguous feeling when visually observed. It is also reliable to measure the absorbance with a spectrophotometer. The European Pharmacopoeia's detection method subtly uses $\mathrm{H}_{3} \mathrm{PO}_{4}$ to mask the color of ferric iron, eliminating the background color of $\mathrm{FeCl}_{3}$, which is basically at the same color level as the standard solution without $\mathrm{FeCl}_{3}$. It is easier, more clear, and more reasonable. The content of ferrous iron can be calculated semi-quantitatively by masking ferric iron with $\mathrm{H}_{3} \mathrm{PO}_{4}$ and spectrophotometric determination of ferrous ion content. Therefore, the method established in this study can more clearly detect whether the ferrous content in ferric chloride hexahydrate is up to standard.

\section{References}

[1] EDQM. European Pharmacopoeia [M] Edqm, 2008: 1882.

[2] The United States Pharmacopeial Convention. U.S. pharmacopoeia [M]. Palala Press, 2015.

[3] ACS Committee on Analytical Reagents. Reagent chemicals: specifications and procedures [M]. OUP USA, New York oxford university press, 2006 (10): 322-324.

[4] British Pharmacopoeia Commission. British pharmacopoeia [M]. The Stationery Office, 2010.

[5] The indian Pharmacopoeia Commission. Indian pharmacopoeia [M]. 2010.

[6] Wang Zhen, Dictionary of Chemical Technology [M]. Beijing: Chemistry Industry Press, 1979 (2): 334.

[7] Department of Inorganic Chemistry, Tianjin University, Inorganic Chemistry [M]. (Third Edition). Beijing: Higher Education Press, 2002: 887.

[8] Yang Shizhong, Zhang Lianyi and Baharguly Kahar, Determination of Vitamin C Utilizing the Reaction of $\mathrm{Fe}^{2+}$ and $\mathrm{K}_{3}\left[\mathrm{Fe}(\mathrm{CN})_{6}\right][\mathrm{J}]$. Journal of Analytical Science, 2005 (05).

[9] Zhang Suijuan, Li Qiongfang and Mo Haihong, Catalytic Spectrophotometric Determination of Trace Mercury with $\mathrm{K}_{4}\left[\mathrm{Fe}(\mathrm{CN})_{6}\right]-\mathrm{K}_{3}\left[\mathrm{Fe}(\mathrm{CN})_{6}\right]$ system [J]. Chinese Journal of Analytical Laboratory, 2007, 26 (3): 80-83.

[10] Б. В. Некрасов, General Chemistry Course (Volume 2) [M]. Beijing: Higher Education Press, 1955: 816.

[11] Piao Fengyu, Zhang Jing'ai, Yu Zheqia, Wu Xinzi, and Jin Dacheng, Identification and Content Determination an the Resultant of Potassium Ferricyanide and Ferric Chloride [J]. Journal of Yanbian University (Natural Science Edition), 1996.

[12] Zheng Liqing, Li Jing, Fan Shunli, Gao Xiaolin and Li Quanmin, Spectrophotometric Determination of Terbutaline Using $\mathrm{K}_{3}\left[\mathrm{Fe}(\mathrm{CN})_{6}\right]-\mathrm{FeCl}_{3} \quad[\mathrm{~J}]$. Chemical Research and Application, 2010, 22 (7).

[13] HG/T3474-2014, chemical reagent ferric chloride hexahydrate (ferric chloride) [S].

[14] Heikki Hellman, Risto S. Laitinen, Leena Kaila, orma Jalonen, Vesa Hietapelto, Jukka Jokela, Arja Sarpola and Jaakko Rämö, Identifification of hydrolysis products of $\mathrm{FeCl}_{3} 6 \mathrm{H}_{2} \mathrm{O}$ by ESIMS [J]. J. Mass Spectrom, 2006 (41): 1421-1429.

[15] Stumm W, Morgan JJ. Aquatic Chemistry; Chemical Equilibria and Rates in Natural Waters [J]. Wiley: New York, 1996 (260). 